\title{
Assessing vulnerability of forest ecosystem in the Indian Western Himalayan region using trends of net primary productivity
}

\author{
Manoj Kumar ${ }^{1}$ (D) $\cdot$ Savita $^{2} \cdot$ Hukum Singh $^{3} \cdot$ Rajiv Pandey $^{4} \cdot$ M. P. Singh ${ }^{5}$. \\ N. H. Ravindranath ${ }^{6} \cdot$ Naveen Kalra $^{7}$
}

Received: 16 May 2018 / Revised: 2 September 2018 / Accepted: 9 November 2018 /

Published online: 12 November 2018

(C) The Author(s) 2018

\begin{abstract}
The Himalayan ecosystem is one of the sensitive and fragile ecosystems with rich biodiversity that provides major ecosystem services. The study was conducted to measure the extent of vulnerability across forested grids of Uttarakhand-one of the States of Indian Western Himalayan (IWH) region. The forests of the state are exposed to various anthropogenic and natural climatic pressures, thus making them vulnerable. In this paper, we demonstrate how to map vulnerability of forest ecosystem by analyzing variability and trends of net primary productivity (NPP). The vulnerability of the forest ecosystem was evaluated through trends of sensitivity and adaptability of NPP. The sensitivity of a system was considered as the response degree of the system to climatic variability whereas adaptability was considered as the ability to maintain, recover or improve its structure in the face of climatic stresses. In our study, NPP was considered as the receptor of shock and stresses of climatic variability and human disturbances. We discuss the method and results with reference to productivity changes under the influence of changing climate for the forested landscape of a mountainous region. The results have been summarized to rank vulnerability at the level of administrative boundary of governance, i.e. district. Average value of vulnerability for all NPP pixels of forests grids in a district was used to compute the vulnerability at district level. The study will help forest managers in decision making for efficiently allocating resources and to prioritize management options in the identified regions to improve productivity in coming times.
\end{abstract}

Keywords Adaptability $\cdot$ Climate change $\cdot$ Forest modelling $\cdot$ MODIS $\cdot$ Sensitivity

Communicated by D. Behera, K. Behera and Sharma.

Manoj Kumar

manojfri@gmail.com

Extended author information available on the last page of the article 


\section{Introduction}

Forests are critical agents for socio-ecological systems of mountains (Pandey and Jha 2012) and provide various kinds of goods and ecosystem services to humans (Costanza et al. 2007). Intergovernmental Panel on Climate Change (IPCC) has clearly flagged that changing climate has impacted the social and ecological systems (IPCC 2014). Therefore, compromised deliverables of forest ecosystems may lead for the challenges to the coexistence of forests and communities. Moreover, researchers argued that the forests are vulnerable to changing climate, occurrence of extreme climatic events and human-induced disturbances (Gerlitz et al. 2017; Sharma et al. 2017). The vulnerability of forest due to climate change is adjudged by changes in the phenological characteristics (Bertin 2008; Pau et al. 2011), tree line shifts (UAPCC 2014), changes in distribution of forest type (Ravindranath and Sukumar 1996; Chaturvedi et al. 2011; Gopalakrishnan et al. 2011; Upgupta et al. 2015; Devi et al. 2018) and forest productivity (Pan et al. 2015; Yongxiang et al. 2015). The productivity and biodiversity of the Himalayan forests are under the influence of climate change (Ravindranath and Sukumar 1996; Gopalakrishnan et al. 2011; Sharma et al. 2015; Upgupta et al. 2015). With this conclusion, it can be argued that the future projected climate led changes in forests would make them vulnerable, which may harm the existing alignment between the forests and communities.

We consider vulnerability as the degree to which a system is susceptible to and is unable to cope with adverse effects. More lucidly, vulnerability is a function of exposure to climate impacts, including variability and extremes, and the sensitivity and adaptive capacity of the system being exposed (Parry et al. 2007). Vulnerability is subject specific and can be explained in many ways (Gallopín 2006; Füssel 2007). Quantification and representation of vulnerability as some numerical value is difficult (Alwang et al. 2001). Developing robust and credible measures of vulnerability is a challenge (Adger 2006) and depends on the choice of definition and measurement protocol (Kurosaki 2010).

Vulnerability assessment of forest ecosystem requires a comprehensive understanding of various biotic and abiotic factors responsible for forest growth (Kumar et al. 2018). The integration of various components would be complex as the intricacies of direct measurement of these factors are very high (Sharma et al. 2013). Vulnerability of forest ecosystem is modulated by stress imposed by climatic changes that is beyond the capacity to overcome or adapt to stress (Blaikie et al. 2014; Pandey and Bardsley 2015) and can be expressed as the difference between sensitivity and adaptability (Yongxiang et al. 2015; Zhang et al. 2017). Sensitivity refers to the response degree of the ecosystem to environmental change, expressed as the inter-annual variability (e.g. trend of NPP) during the period of assessment for ecosystem under evaluation (Yongxiang et al. 2015; Zhang et al. 2017). Ecosystem adaptation signifies the self-regulation tool of the ecosystem, regarded as a measure of maintenance of the system in a relatively stable state (IPCC 2014; Sharma et al. 2017). The deviation in steady state, a measure of adaptation is determined by the trend of the variability of an ecosystem during a fixed period (Coulson and Joyce 2006).

The vulnerability of forest describes particularly the degree of alteration of forest type distributions and carbon-related functions (such as NPP expressed as Mg carbon ha ${ }^{-1}$ year $^{-1}$ and soil organic carbon) due to climate change. In recent years, various methods and models have evolved and have been applied for the assessment of forest vulnerability (Quillet et al. 2010; Chaturvedi et al. 2011; Zhang et al. 2017; Kumar et al. 2018). Most of these methods and models assume forest deliverable such as NPP as a dependent observational entity with the consideration that the entity has compounded impacts of all 
biotic and abiotic factors (Yongxiang et al. 2015; Zhang et al. 2017). NPP, the difference between gross primary productivity (GPP) and autotrophic respiration (AR), is resultant of the various physiological processes of the plant as per the biotic and abiotic structure associated with the plant. Spatial and temporal variations of NPP is influenced by several factors including climate change (Cao et al. 2004; Li et al. 2015). NPP is commonly used as an index to reflect ecosystem response to climate change (McCarthy 2001) and has been shown to correlate with the total value of ecosystem services (Costanza et al. 1998). NPP is the most variable part of the terrestrial carbon cycle and greatly affects inter-annual variations of terrestrial carbon sinks (Cramer et al. 1999). An increase in temperature, for example, could extend the growing season and enhance the NPP (Myneni et al. 1997). These attributes of NPP supported us to focus on NPP trend over a period of climate observation as a measure of sensitivity, adaptability and vulnerability as also suggested by Zhang et al. (2017).

Study at regional level focusing trend analysis of NPP are not available (Jha and Srivastava 2018) although studies have been done over the country level NPP (Nayak et al. 2010; Bala et al. 2013). The terrestrial NPP of India, its quantum, spatial variability, and distribution across seasons is not well understood (Chhabra and Dadhwal 2004). Bala et al. (2013) examined the role of abiotic factors such as temperature, precipitation, atmospheric $\mathrm{CO}_{2}$ concentration, soil water and downward surface solar radiation on the evolution of NPP at national level for India and it was observed that increasing trend of NPP is driven by these abiotic factors. Productivity is under the influence of climatic parameters (Zhang et al. 2014) and productivity of global terrestrial ecosystems are associated with temperature and precipitation ( $\mathrm{Li}$ et al. 2015). For Indian Forests, NPP is driven by $\mathrm{CO}_{2}$ concentration followed by precipitation and temperature (Bala et al. 2013). Chhabra and Dadhwal (2004) calculated area-weighted terrestrial NPP of India. However, the study lacked analysis of influence of climatic factors. Furthermore, Bala et al. (2013) studied the trends of NPP for entire India along with the analysis of its relationship with climatic parameters.

\section{Materials and methods}

\section{Study area}

The study was conducted in the state of Uttarakhand $\left(28^{\circ} 43^{\prime}-31^{\circ} 28^{\prime} \mathrm{N}, 77^{\circ} 34^{\prime}-81^{\circ} 03^{\prime} \mathrm{E}\right)$ (Fig. 1), a part of Indian Western Himalayan (IWH) region. The IWH region is a megabiodiversity zone having water catchment for a number of rivers that provides water to the downstream states for agriculture and consumption. The region indirectly feeds a significant section of the country's population (Ministry of Environment \& Forests 2010). The geographical area of Uttarakhand state is $53,483 \mathrm{~km}^{2}$, extending approximately $320 \mathrm{~km}$ in east-west and $250 \mathrm{~km}$ in north-south direction. The state has tropical to temperate climate. The temperature in the state ranges from sub-zero in winter to $43^{\circ}$ in summer (FSI 2015). The average annual rainfall is $1550 \mathrm{~mm}$. Total forest cover of the State is $38,000 \mathrm{~km}^{2}$, which is $63.42 \%$ of its geographical area (FSI 2017). Dominant forest type groups according to the Champion and Seth (1968) classification includes Himalayan moist temperate forests, sub-tropical pine forests, tropical moist deciduous forests (FSI 2011) (Fig. 2). The soil types in the state are alluvial, alluvial mixed with boulders and shingles, alluvial sandy soil, residual sandy loam, sandy loam, red to dark and red to black clay (UAPCC 2014). 


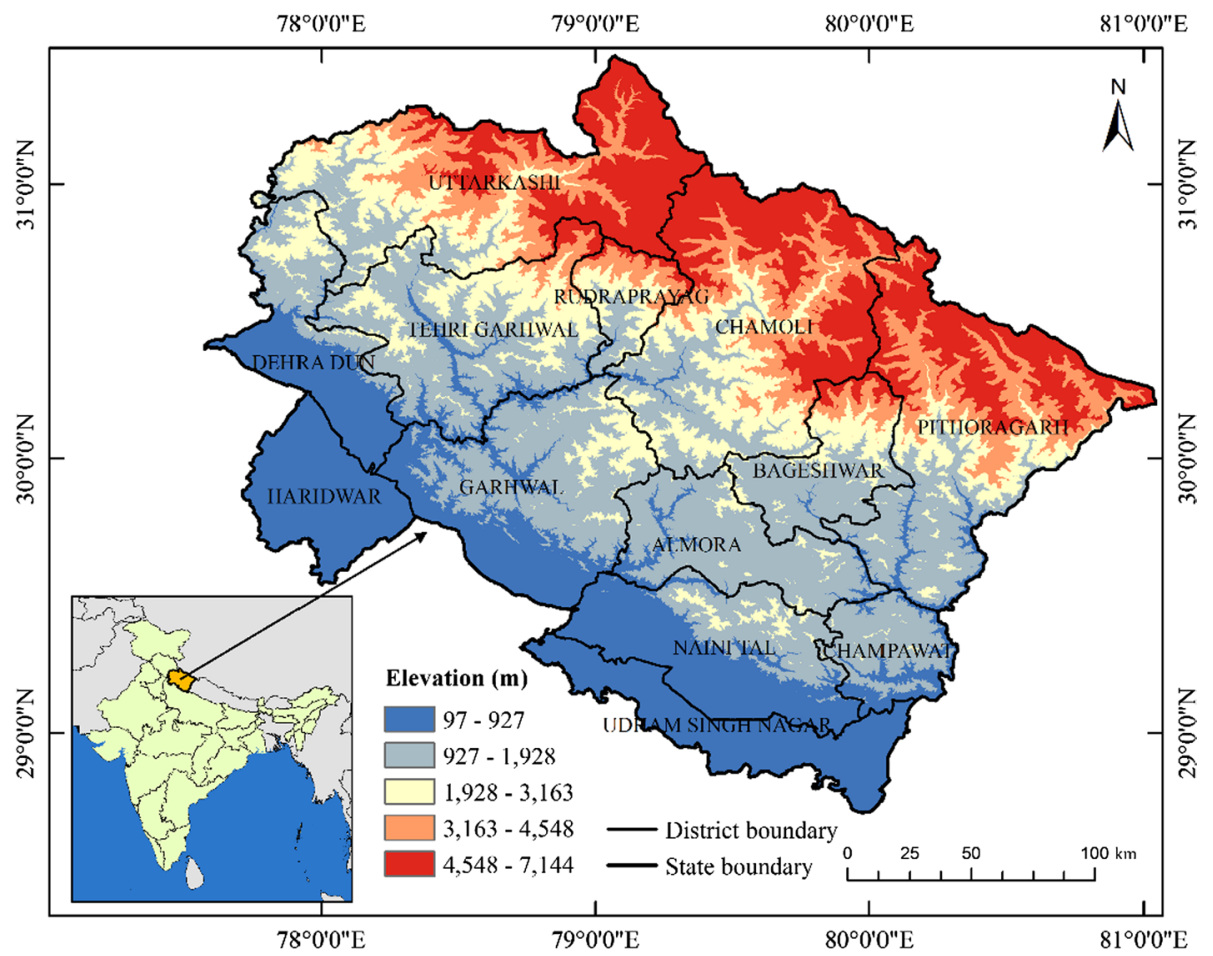

Fig. 1 Location of the study area showing elevation ranges derived from NASA Shuttle Radar Topography Mission Digital Elevation Model (SRTM DEM) (https://earthexplorer.usgs.gov/)

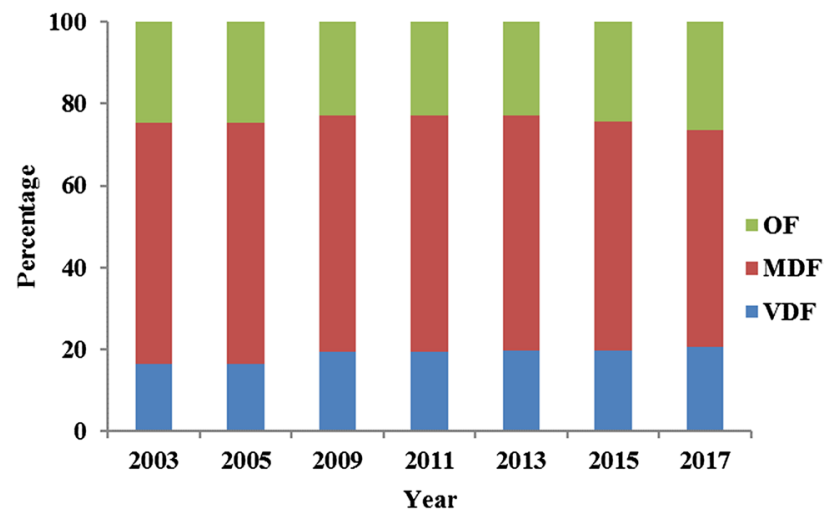

Fig. 2 Percentage distribution of forest density classes during Forest Survey of India (FSI) assessment years 2003-2017. $O F$ open forest, $M D F$ moderately dense forest, $V D F$ very dense forest

The comparison of forest cover density classes during the Forest Survey of India (FSI) assessment period of 2003-2017 reveals that the area under very dense cover and open forest has increased by 24.16 and $6.6 \%$, respectively; while moderately dense has decreased by $10.65 \%$ (Fig. 3); with an overall loss of forest area by $0.69 \%$. The decrease in forest area is attributed to management practices, diversion of forest lands for developmental 


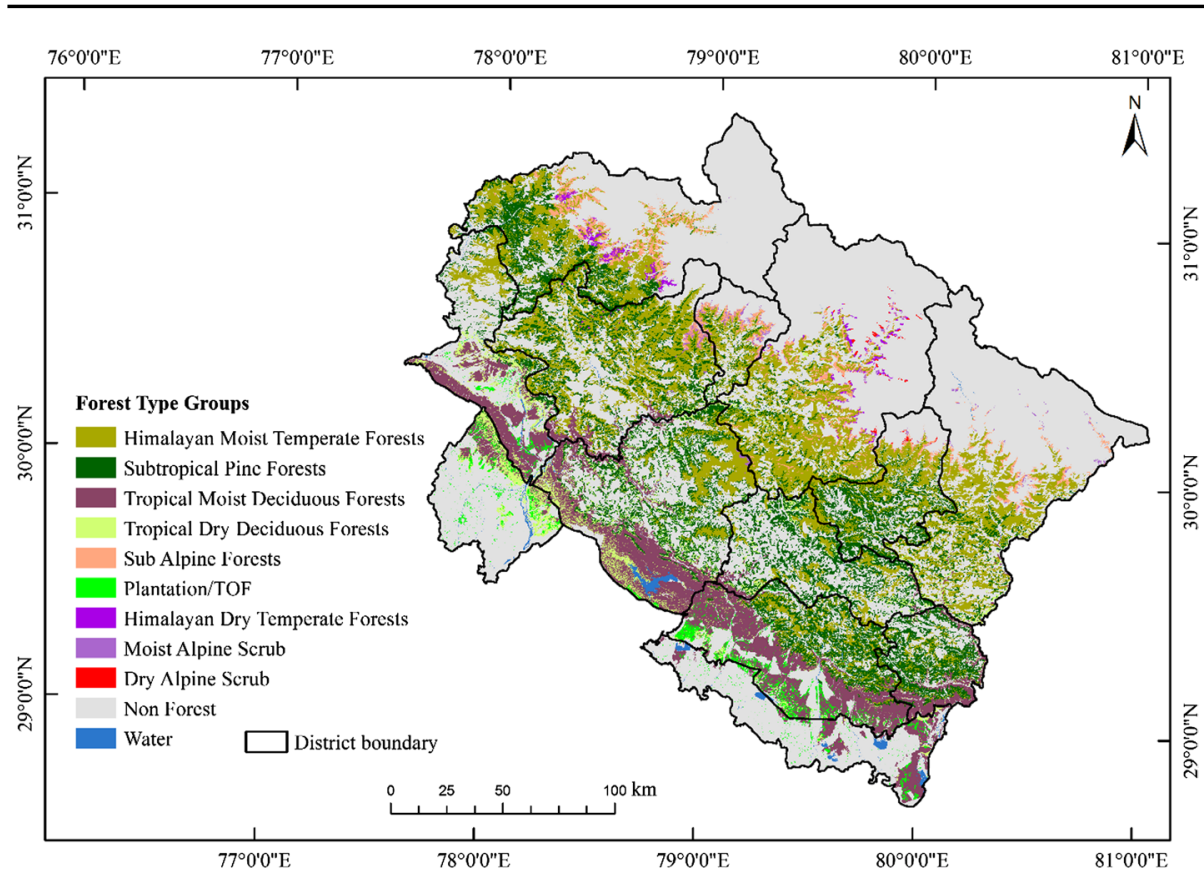

Fig. 3 Forest type groups of the study area [derived from FSI (2011) digital layer]

activities (FSI 2015), and increasing pressure on the forest area by the local population (Pandey et al. 2014; Malik et al. 2016). Long-term trends in the maximum, minimum, and mean temperatures over the region during the 20th century suggest a significant rise in air temperature, with winter warming occurring at a faster rate (Bhutiyani et al. 2007). Extent of climatic variability and periodic occurrence of extreme episodic events have been major concerns of the region in recent decades (UAPCC 2014). The study area constitutes of a complex terrain with different altitudes and orientations leading to diverse impacts of climate change with likely impacts on ecosystems in terms of increase in forest fires, increase in glacier melt, shifting of potential habitats of several species and changes in productivity of agricultural and forestry systems. Extent of climatic variability and periodic occurrence of extreme episodic events have been major concerns of the region in recent decades. The ecosystem of the region is frequently exposed to climatic and human induced disturbances which have influence over the net productivity.

\section{Data sources and method}

\section{NPP data, climatic variables and software used}

Remotely sensed data of U.S. National Aeronautics and Space Administration (NASA) Earth Observing System (EOS) of Moderate Resolution Imaging Spectroradiometer (MODIS) was used to obtain the estimate of annual NPP $\left(\mathrm{Mg}-\mathrm{C} \mathrm{ha}^{-1}\right.$ year $\left.^{-1}\right)$ at $500 \mathrm{~m}$ spatial resolution (Running et al. 2015). The modelled annual NPP (MOD17A3H) since 2000 and continuing to the present are archived at NASA DAAC-Distributed Active Archive Center (DAAC 2008). Spatial layers of annual NPP for the period 2000-2014 
were downloaded as NetCDF file (Rew and Davis 1990) at $500 \mathrm{~m}$ spatial resolution from the NASA DAAC archive and the climatic variables of 11 years (2004-2014) observations for Mean Temperature (TMP, ${ }^{\circ} \mathrm{C}$ ), Total Precipitation (PRE, mm) and Wet days' frequency (WET, rain days per month) were obtained from the Climatic Research Unit (CRU), University of East Anglia (UEA), UK (CRU TS v. 4.01) (Harris et al. 2014) as NetCDF format at 30 min spatial resolution. Climate Data Operator (CDO) software (Schulzweida et al. 2006) was used to process NetCDF files for the analysis of variability and trend. Nearest neighbour remapping method of CDO was used to upscale NPP from $500 \mathrm{~m}$ to the grid size resolution of 5 and $30 \mathrm{~min}$ for the analysis and visual representation. ArcGIS (10.1) software was used for the cartographic representation. The values of NPP were carefully scrutinized and inconsistency in the data was observed between the years 2001 and 2003 which have significantly high values in comparison to other years, therefore only the consistent data sets of years 2004-2014 were considered for the vulnerability analysis.

\section{Trend analysis of NPP and calculation of vulnerability}

Entire study area was divided into grids of size $0.5^{\circ} \times 0.5^{\circ}$ (i.e. $30 \mathrm{~min}$ ) equivalent to the grid size of available climatic data. All those grids having its geographical area $>5 \%$ under forest cover were marked as "forest grids". Such grids are 22 in number (Fig. 4). Vulnerability analysis was done only for those identified forested grids by analyzing the trend of NPP for the period 2004-2014 at a spatial resolution of $5 \mathrm{~min}$. We used the concept of

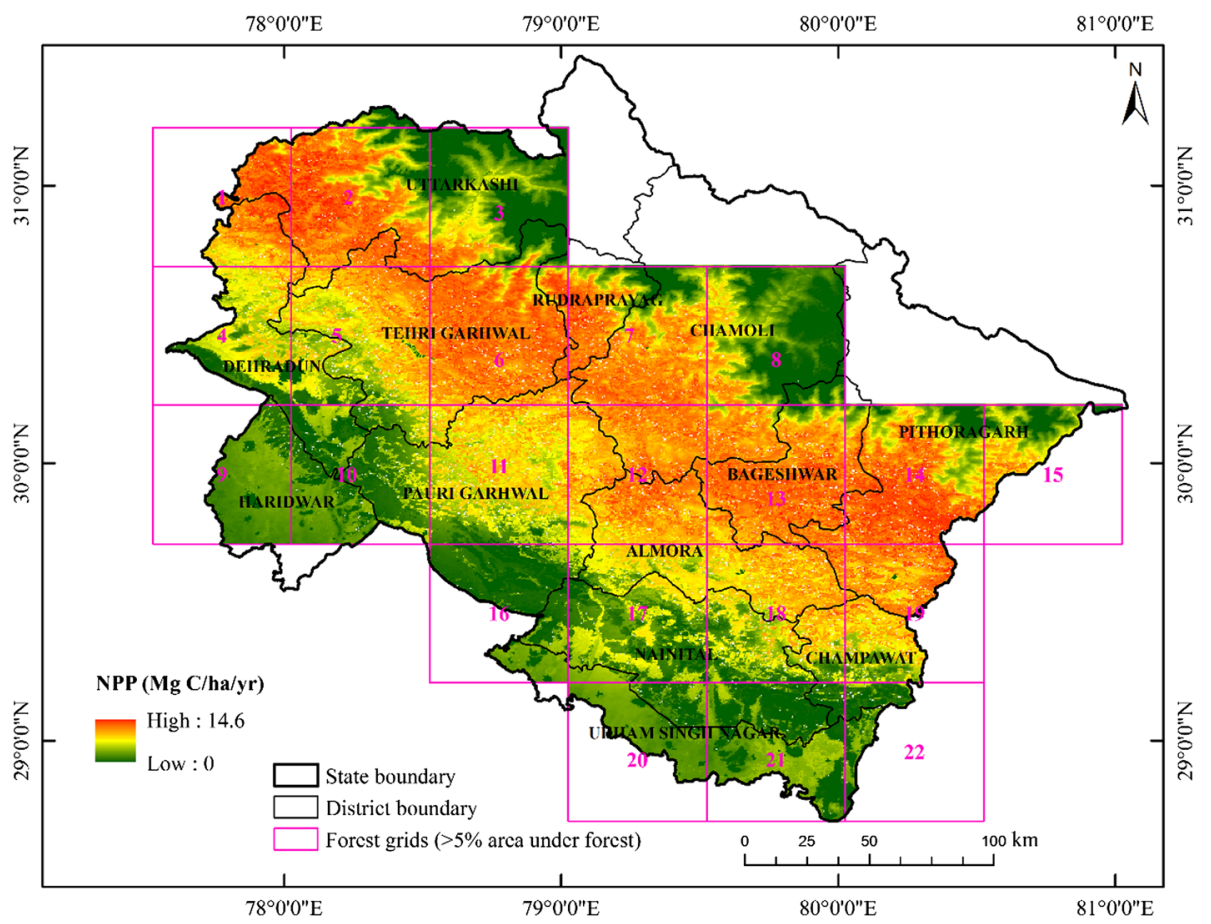

Fig. 4 Spatial distribution of MODIS derived NPP over forest grids (averaged value for the period 20042014) 
vulnerability that combines the two criteria, sensitivity and adaptability. The vulnerability of the ecosystem can be expressed as:

$$
V=S-A
$$

where $V, S$, and $A$ represent the vulnerability, sensitivity and adaptability of the ecosystem, respectively (Yongxiang et al. 2015; Zhang et al. 2017). For a particular ecosystem, sensitivity refers to the response degree of the ecosystem to environmental change, expressed as the inter-annual variability of NPP during the period. The sensitivity was considered as the inter-annual fluctuation of ecosystem function (Zhang et al. 2017) and calculated as the degree of dispersion of the average value from 2004 to 2014.

$$
S=\sum_{i=1}^{n}\left|F_{i}-\bar{F}\right| / \bar{F}
$$

where $S$ is the sensitivity of the ecosystem, $F_{i}$ is the value of NPP during the period (2004-2014), $\bar{F}$ is the average value of NPP for the 'n' number of years.

Ecosystem adaptation signifies the self-regulation tool of the ecosystem, regarded as a measure of maintenance of the system in a relatively stable state. For a certain period, the trend of variability of an ecosystem is used to measure its deviation from the steady-state and referred as ecosystem adaptation (Coulson and Joyce 2006). The system tends to be relatively stable, if the change trend of variability is reduced or unchanged, whereas an increase in variability suggests an unstable system to adapt to the environmental change and indicates increase in the vulnerability. The adaptation was considered as the maintenance of the relatively stable state or improvement of the ecosystem over a period of assessment in spite of exposure to stressors. The trend of adaptability was expressed by the slope of the linear fitting trend line for the inter-annual variability of the NPP, where increasing NPP trend over a period in spite of exposure to stressors suggests for greater adaptability.

$$
y=a x+b
$$

where $x$ refers to the natural numbers $1,2,3 \ldots$, corresponding to the years from 2004 to 2014, $y$ is the NPP over observation period and $a$ is the adaptability (trend of NPP variability).

Thematic layers of the sensitivity, adaptability and vulnerability were categorized into four classes namely, low, medium, high and very high classes using ArcGIS 10.1 software using natural breaks (Jenks) algorithm for the forested grids keeping pixel cell size at a resolution of $5 \mathrm{~min}$. Average value of vulnerability for all NPP pixels within a grid size of $0.5^{\circ}$ was used to compute the vulnerability at forest grid level; while for calculating the vulnerability at districts level, the averaged value of the pixels within districts were used. The same protocol was followed to map the sensitivity and adaptability at forest grid and district levels.

\section{Results and discussions}

\section{Variation of NPP}

Spatial variation of the mean NPP and standard deviation over the period (2004-2014) ranged between 0-14.6 Mg-C ha year $^{-1}$ (Fig. 4) and 0-6.54 Mg-C ha ${ }^{-1}$ year $^{-1}$ (Fig. 5), 


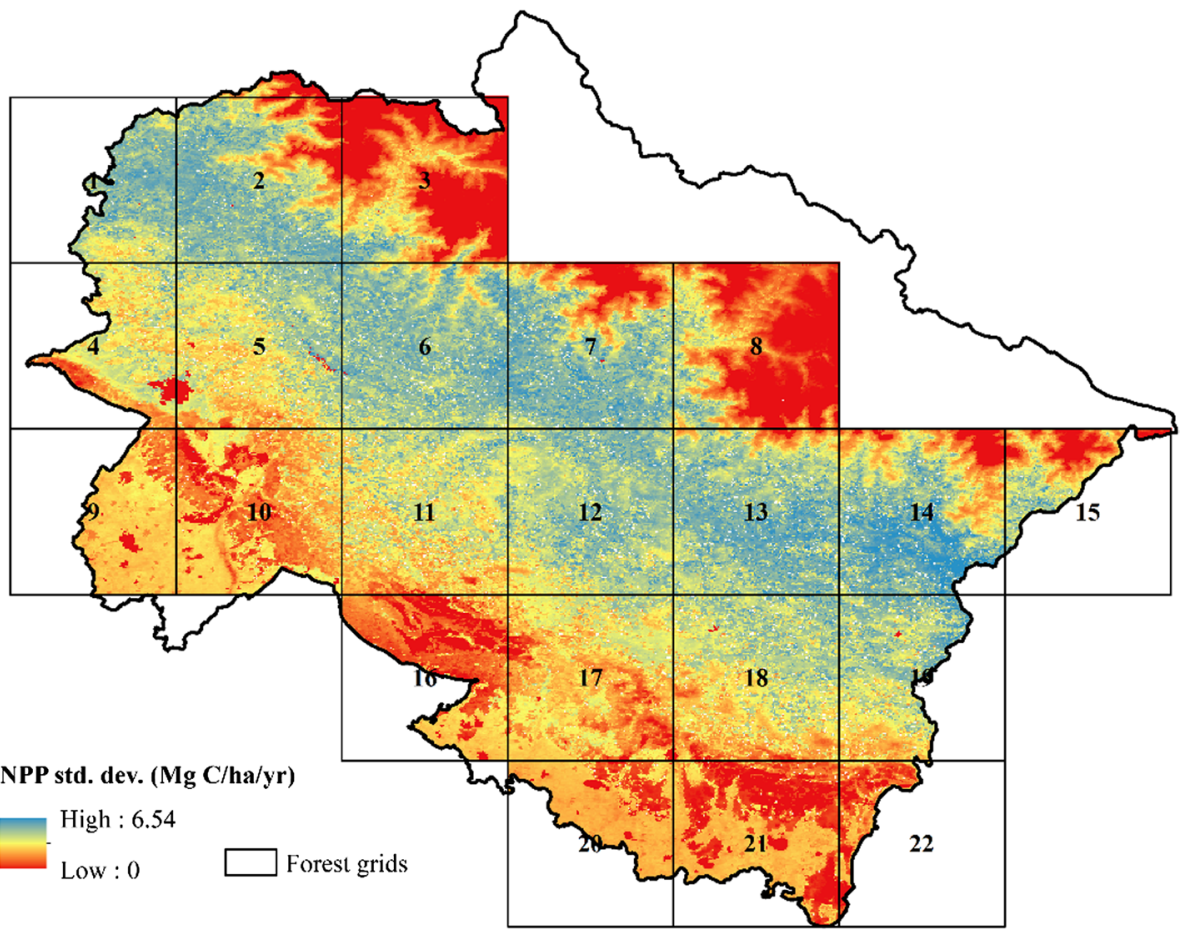

Fig. 5 Spatial pattern of MODIS derived standard deviation of NPP for the period 2004-2014

respectively. Chhabra and Dadhwal (2004) reported area-weighted terrestrial NPP of India as 6.66 Mg-C ha- year $^{-1}$ for the period June 1998-May 1999 using SPOT-VEGETATION 10-day NPP composites. Bala et al. (2013) estimated Advanced Very High Resolution Radiometer (AVHRR)-derived NPP for the Indian Himalayan forests as $\sim 8 \mathrm{Mg}-\mathrm{C} \mathrm{ha}^{-1}$ year $^{-1}$. The spatial average NPP during 2004-2014 for the study region ranged between 3.41 and $4.06 \mathrm{Mg}-\mathrm{C} \mathrm{ha}^{-1} \mathrm{year}^{-1}$. NPP has an increasing temporal trend during the period 2004-2014 (Fig. 6) with the mean, standard deviation and standard error of estimate as $3.72 \mathrm{Mg}-\mathrm{C} \mathrm{ha}^{-1}$ year $^{-1}, 0.21 \mathrm{Mg}-\mathrm{C} \mathrm{ha}^{-1}$ year $^{-1}$ and $0.06 \mathrm{Mg}-\mathrm{C} \mathrm{ha}^{-1}$ year $^{-1}$, respectively. Bala et al. (2013) also observed increasing trends of AVHRR-derived NPP over India for the assessment period 1982-2006. They reported that the fluctuation in the NPP estimate between the years may be guided by the biotic and abiotic influences.

\section{Spatial pattern of climatic variables and its relationship with NPP}

We analyzed the spatial pattern of precipitation and temperature and attempted to establish relationship between climatic parameters and NPP for the study region. The average annual temperature of the region varied from 6 to $25.30{ }^{\circ} \mathrm{C}$ (Fig. 7a). The regions of high productivity were mainly concentrated in the areas of middle range temperature, while the regions with very high or very low temperature depict low productivity (Fig. 4). Productivity of the region was also influenced by the amount of rainfall and the number of rain days in a month. Averaged annual precipitation ranged between 57.62 and $92.08 \mathrm{~mm}$ (Fig. 7b), while the wet day's frequency ranges between 3 and 
Fig. 6 Temporal evolution of spatial distribution of 15 years (2000-2014) averaged NPP.

Exceptionally high values of NPP are shown in oval circle. NPP values not considered for this study is shown as red squared dots

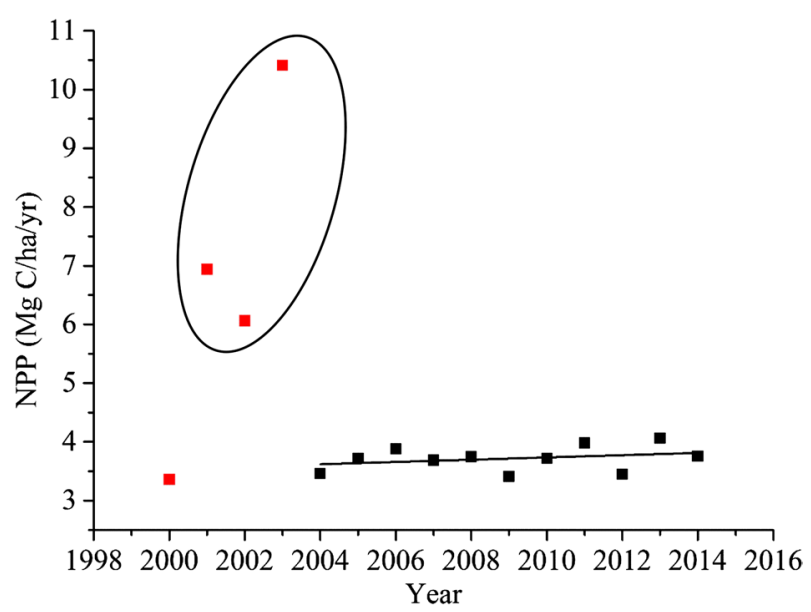

6 rain days per month (Fig. 7c). Regions with high productivity were mainly concentrated in forests which receive high rainfall and higher number of monthly rain day's frequency. Relationship of three climatic variables (TMP, PRE and WET) was established with the NPP using correlation coefficient (r) and it was observed that there is very weak negative relationship of NPP with TMP $(\mathrm{r}=-0.06)$ (Fig. 8a) while PRE and WET depicts a strong positive correlation with NPP having "r" value of 0.83 (Fig. 8b) and 0.85 (Fig. 8c), respectively. The relationship of TMP with NPP suggests that with increasing temperature productivity declines while the total rains and number of rainy days increases the productivity. It can be assumed that climatic variables act as one of the important stressors which have a greater influence on the productivity and thus vulnerability of a forest ecosystem.

\section{Spatial pattern of Sensitivity, Adaptability and Vulnerability}

Sensitivity, adaptability and vulnerability based on the assessment of NPP were categorized into four classes (low, medium, high and very high) for the assessment period 2004-2014 (Table 1). Sensitivity of most of the region lies between high $(59.58 \%)$ to very high $(22.95 \%)$ classes, adaptability of the region mostly falls under high $(33.85 \%)$ and low $(23.78 \%$ ) classes, while vulnerability of the region is mostly dominated by high $(59.42 \%)$ and very high $(23.12 \%)$ classes. The spatial pattern of sensitivity, adaptability and vulnerability of the region is shown in Figs. 9, 10 and 11, respectively. Our results suggest that the forests with low, medium, high and very high vulnerability classes accounted for $5.91,11.52,59.42$, and 23.12 percent of total forests area. The region of high and very high vulnerability classes are mostly concentrated in the middle and high altitudes. Lower altitudes have relatively low vulnerability which suggests that forests of higher altitudes demand better management practices to sustain the productivity. Although, the vulnerability has been deduced from the individual pixel values of sensitivity and adaptability, it was observed that raking of sensitivity and vulnerability of districts are same. This suggest that vulnerability is mostly guided by the sensitivity whereas adaptability has lesser influence on deciding vulnerability ranking of districts. 
Fig. 7 Spatial distribution of 15 years (2004-2014) averaged observations: a mean temperature (TMP, $\left.{ }^{\circ} \mathrm{C}\right), \mathbf{b}$ total precipitation (PRE, $\mathrm{mm}$ ), $\mathbf{c}$ wet days' frequency (WET, rain days per month)
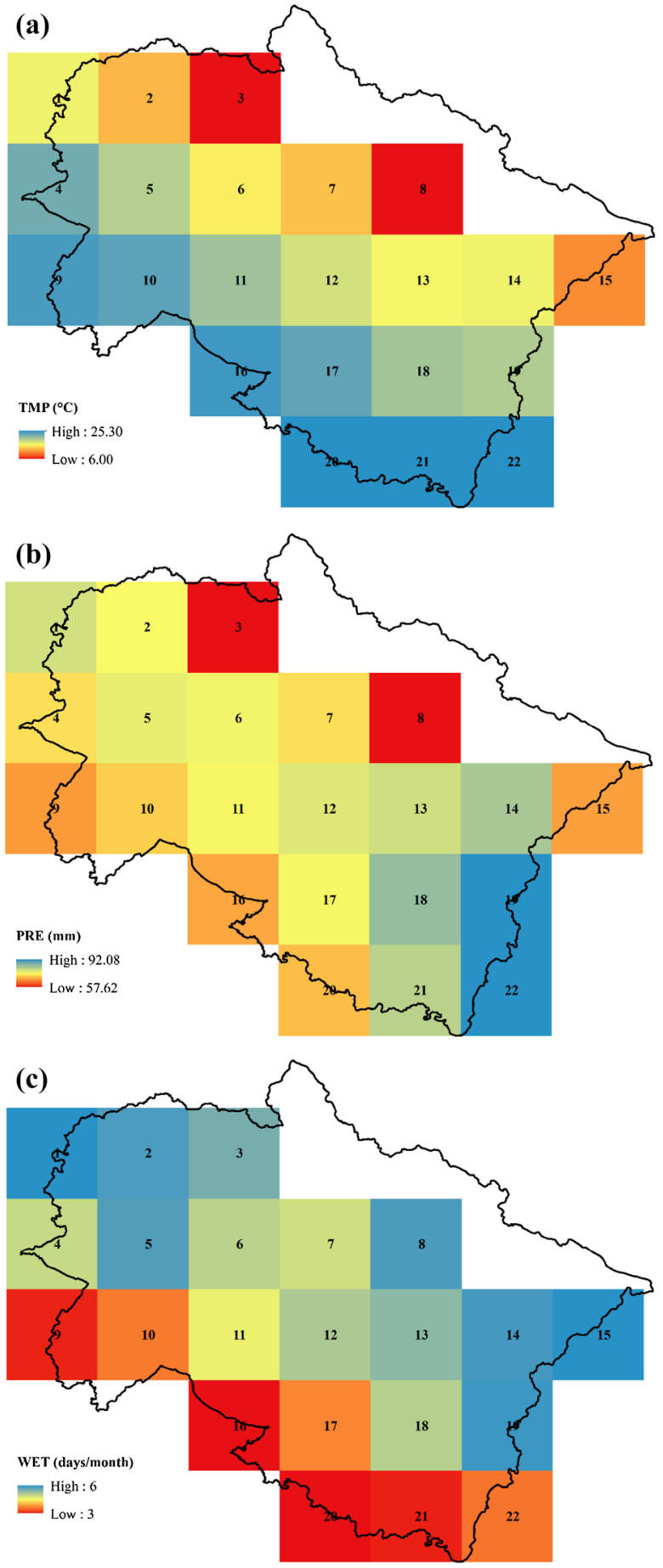

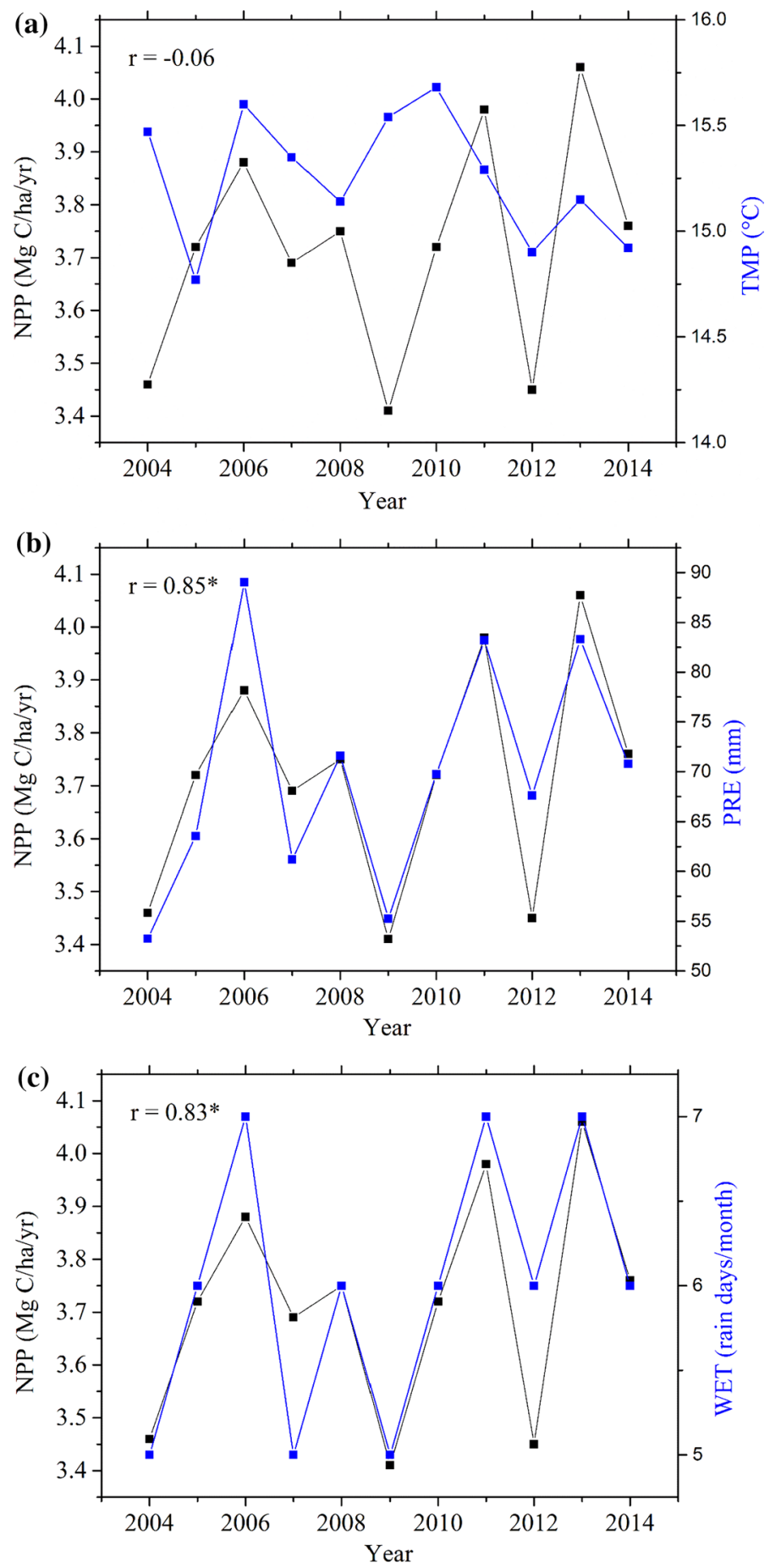

Fig. 8 Spatial averaged values: a mean temperature (TMP), b total precipitation (PRE), c wet days' frequency (WET) and their correlation with spatial averaged NPP; for the period 2004-2014. In each panel, the correlation ( $r$, * shows significant relationship) between NPP and climatic variables is also shown 
Table 1 Area and percentage under different classes of sensitivity, adaptability and vulnerability of the forest grids of Uttarakhand

\begin{tabular}{|c|c|c|c|c|c|c|}
\hline \multirow[t]{2}{*}{ Class } & \multicolumn{2}{|l|}{ Sensitivity } & \multicolumn{2}{|l|}{ Adaptability } & \multicolumn{2}{|c|}{ Vulnerability } \\
\hline & Area $\left(\mathrm{km}^{2}\right)$ & Percentage & Area $\left(\mathrm{km}^{2}\right)$ & Percentage & Area $\left(\mathrm{km}^{2}\right)$ & Percentage \\
\hline Low & 2719.06 & 5.90 & $10,957.05$ & 23.78 & 2724.36 & 5.91 \\
\hline Medium & 5329.35 & 11.57 & $10,513.44$ & 22.82 & 5314.72 & 11.52 \\
\hline High & $27,444.08$ & 59.58 & $15,593.24$ & 33.85 & $27,425.84$ & 59.42 \\
\hline Very high & $10,573.23$ & 22.95 & 9008.79 & 19.55 & $10,663.72$ & 23.12 \\
\hline
\end{tabular}

\section{Ranking of districts on the basis of sensitivity, adaptability and vulnerability}

Ranking of districts for the sensitivity, adaptability and vulnerability based on the analysis of NPP is presented in Fig. 12 and Table 2. The analysis suggests that forests in the districts of higher and middle altitudes such as Pithoragarh, Chamoli, Uttarkashi, Tehri Garhwal, Rudraprayag, Almora, and Bageshwar have the highest sensitivity of productivity. Forests of Nainital, Udham Singh Nagar, Dehradun, Champawat, Pauri Garhwal and Haridwar lying in relatively lower altitudes have the highest adaptability. Vulnerable forests are mostly concentrated in the districts of higher and middle altitudes having ranking similar to the sensitivity and it was found that forests of Pithoragarh, Chamoli, Uttarkashi, Tehri Garhwal, Rudra Prayag, Almora and Bageshwar are the most vulnerable ones (Table 2).

\section{Conclusion}

Productivity (NPP) and its inter-annual fluctuations can be used to measure the vulnerability of a forest ecosystem under the influence of climate change. The analysis of NPP during the period 2004-2014 and its relationship with climatic variables suggest that NPP is predominantly driven by the precipitation and number of wet days' frequency. The analysis reveals that $80 \%$ forests of the region are sensitive to the climate, however, less than half of the forest area has the capacity to bounce back to the impacts of climate change. Therefore, it is imperative to further investigate the potential options for improving the adaptive capacity of the forests at one side and evaluate the causes and remedial measures for reducing the sensitivity of the forest of the region, on the other side. Moreover, under the current dynamics of the forests, more than three quarter of forest area is vulnerable. The actions to reduce vulnerability would be highly desired as most of the vulnerable areas are at the middle and high altitudes where large habitation is dependent on the forest resources for their subsistence (Pandey 2013).

The trend analysis of NPP and resultant vulnerability matrices can be a potential tool for prioritizing forest management actions in a region to sustain productivity and overall conservation of forests. The study will assist the modeler and forest mangers across the world who wishes to understand the intricate relationship between forest growth and climate under the constraints of data scarcity. The study provides a direction to consider biological phenomenon for modelling vulnerability with respect to climate change. Moreover, the finding supports that trend analysis of NPP can be a tool for evaluating forest growth under the changing paradigm of climate. 

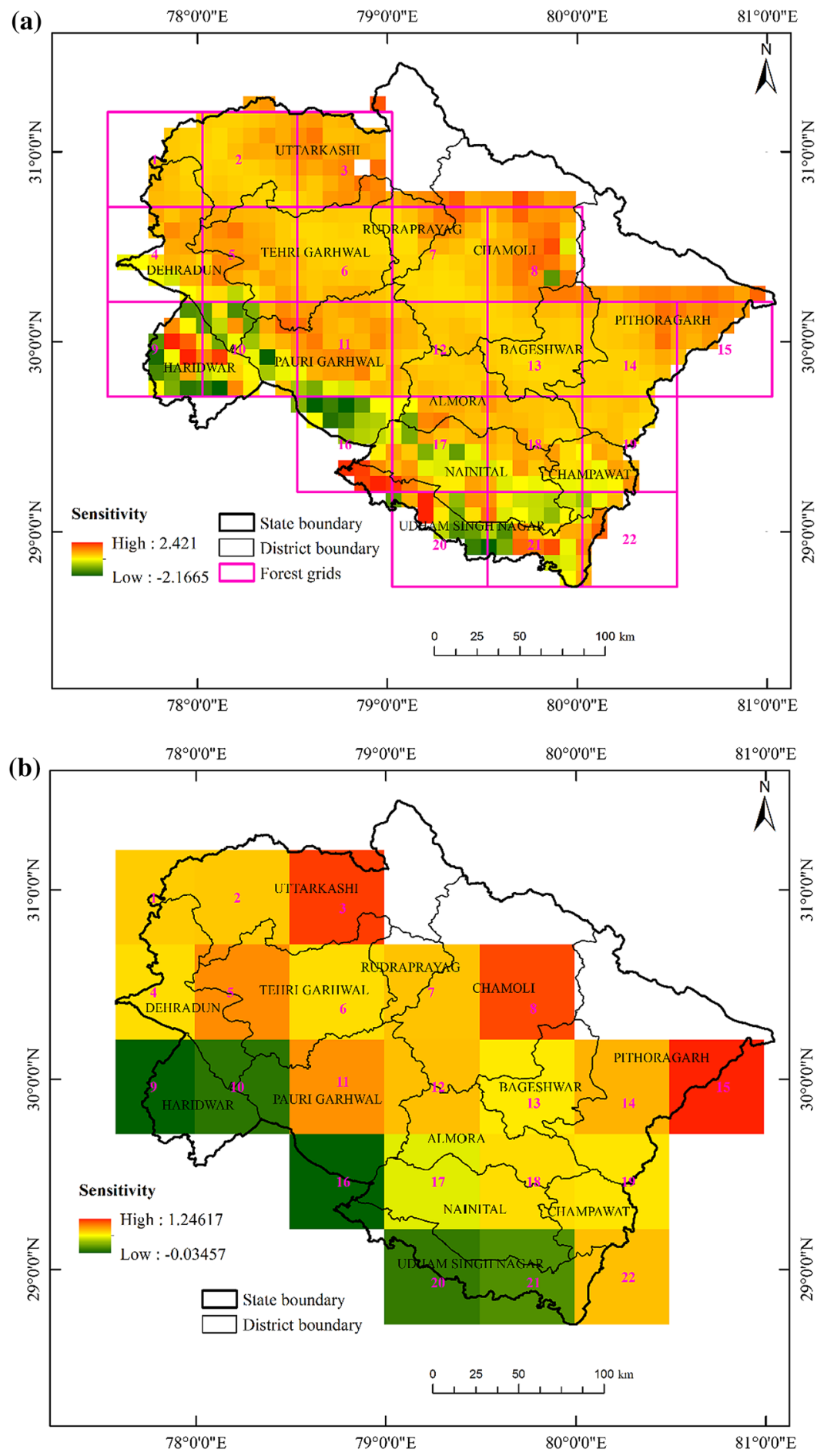

Fig. 9 Spatial variation of sensitivity of productivity (NPP) for the assessment period 2004-2014: a at 5-min pixel resolution, $\mathbf{b}$ averaged value at forest grid level 

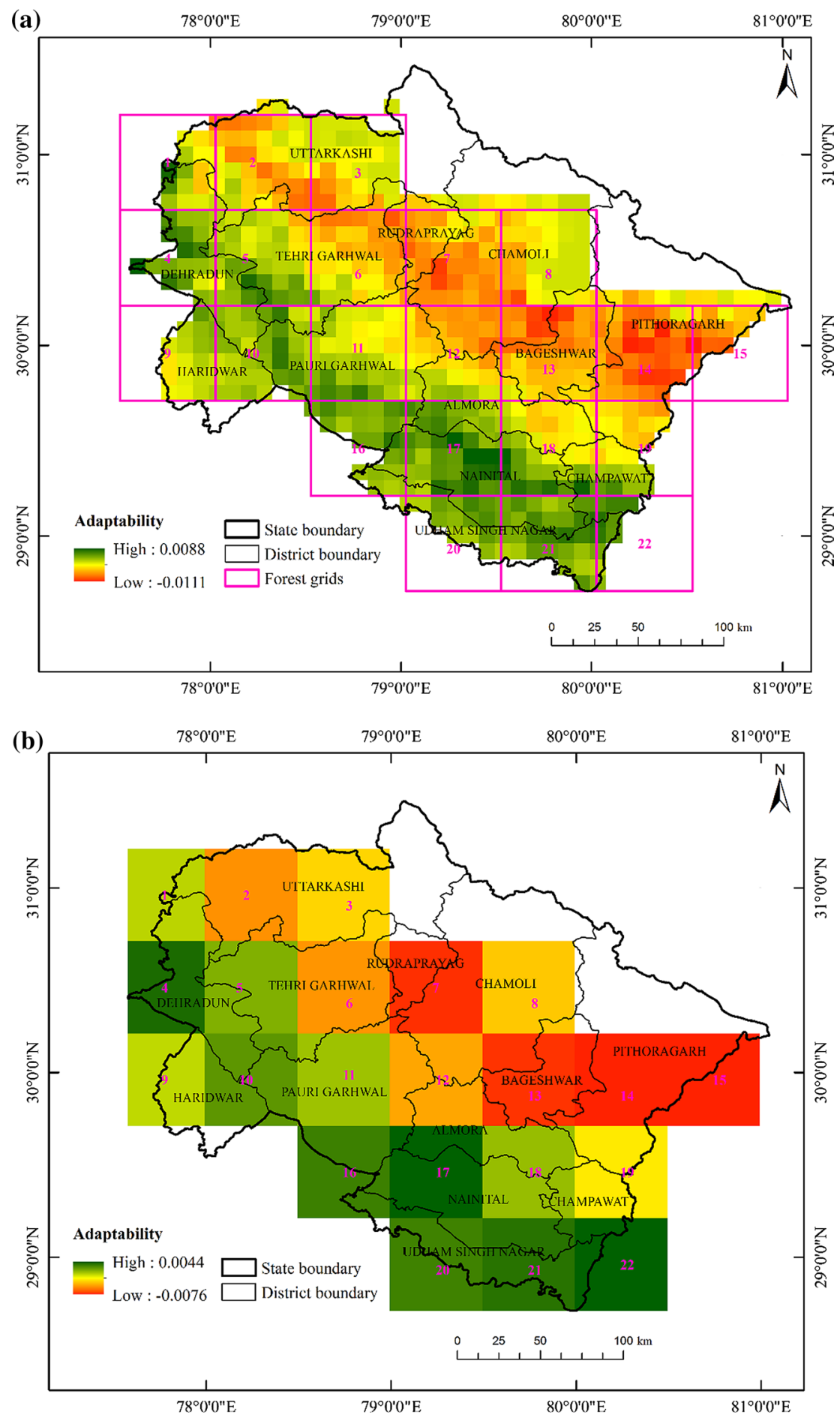

Fig. 10 Spatial variation of adaptability of productivity (NPP) for the assessment period 2004-2014: a at 5-min pixel resolution, b averaged value at forest grid level 

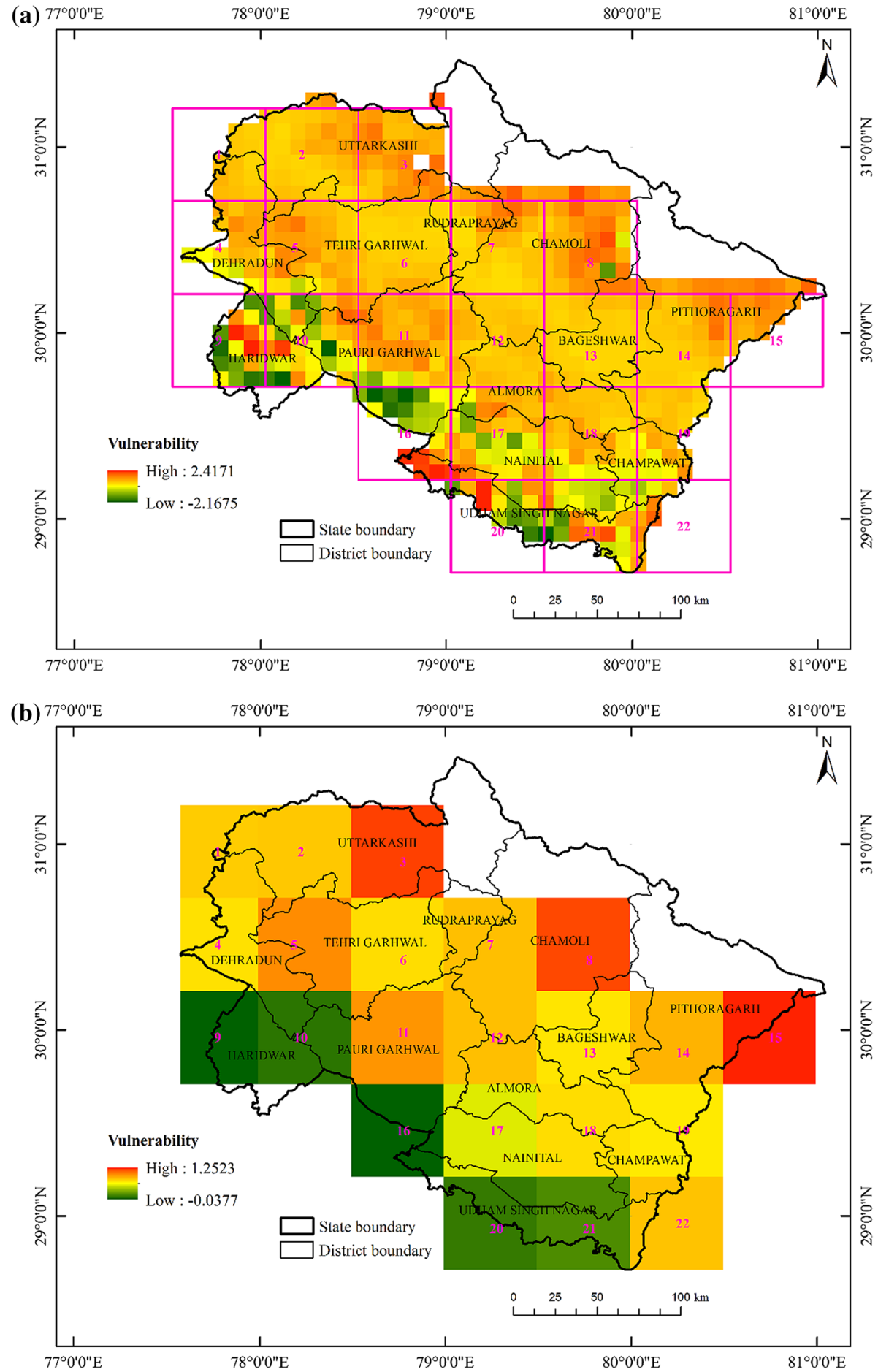

Fig. 11 Spatial variation of vulnerability of productivity (NPP) for the assessment period 2004-2014: a at 5-min pixel resolution, $\mathbf{b}$ averaged value at forest grid level 

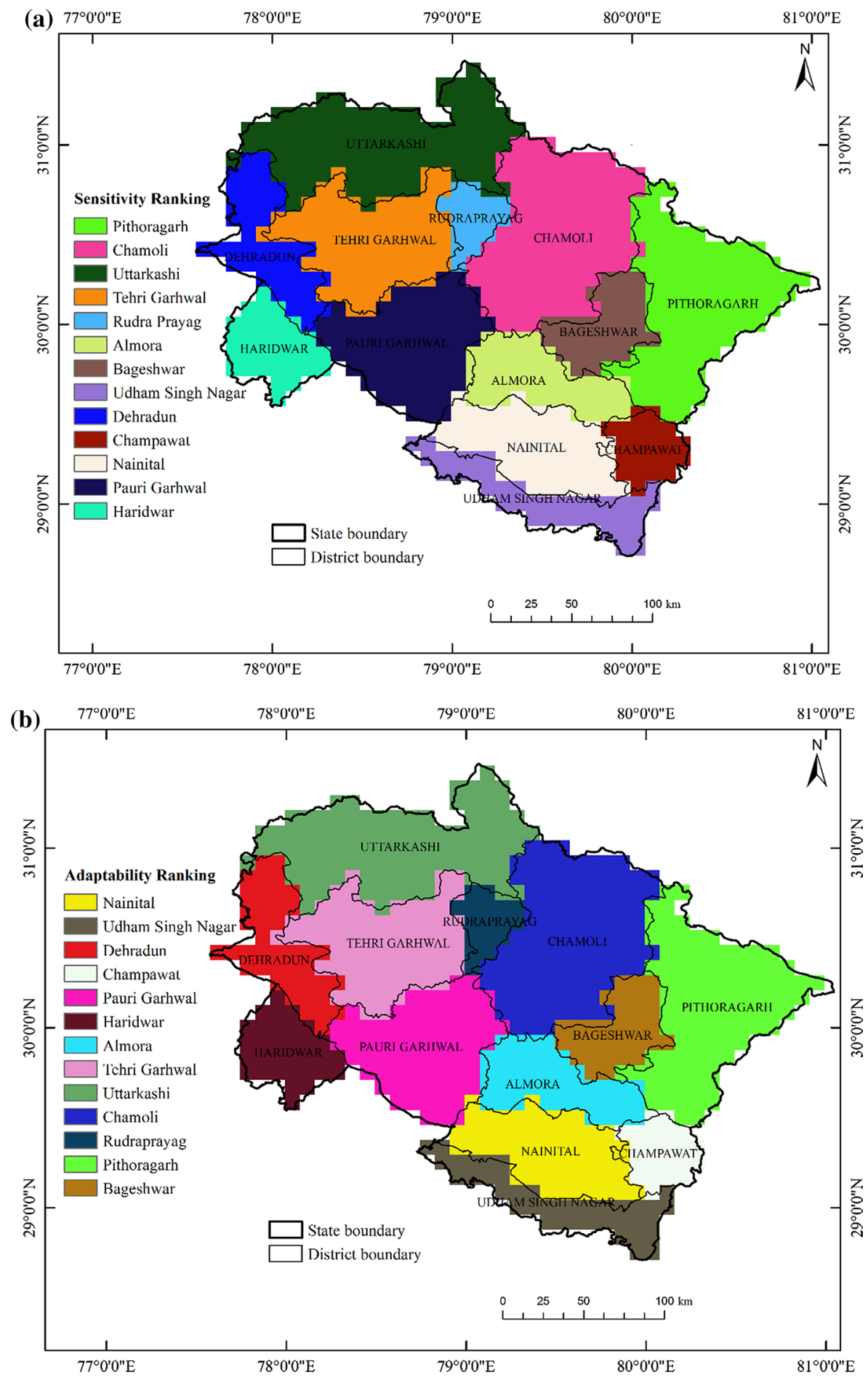

Fig. 12 Ranking of districts (in decreasing orders) based upon the assessment of productivity (NPP) during period 2004-2014: a sensitivity ranking, b adaptability ranking, c vulnerability ranking 


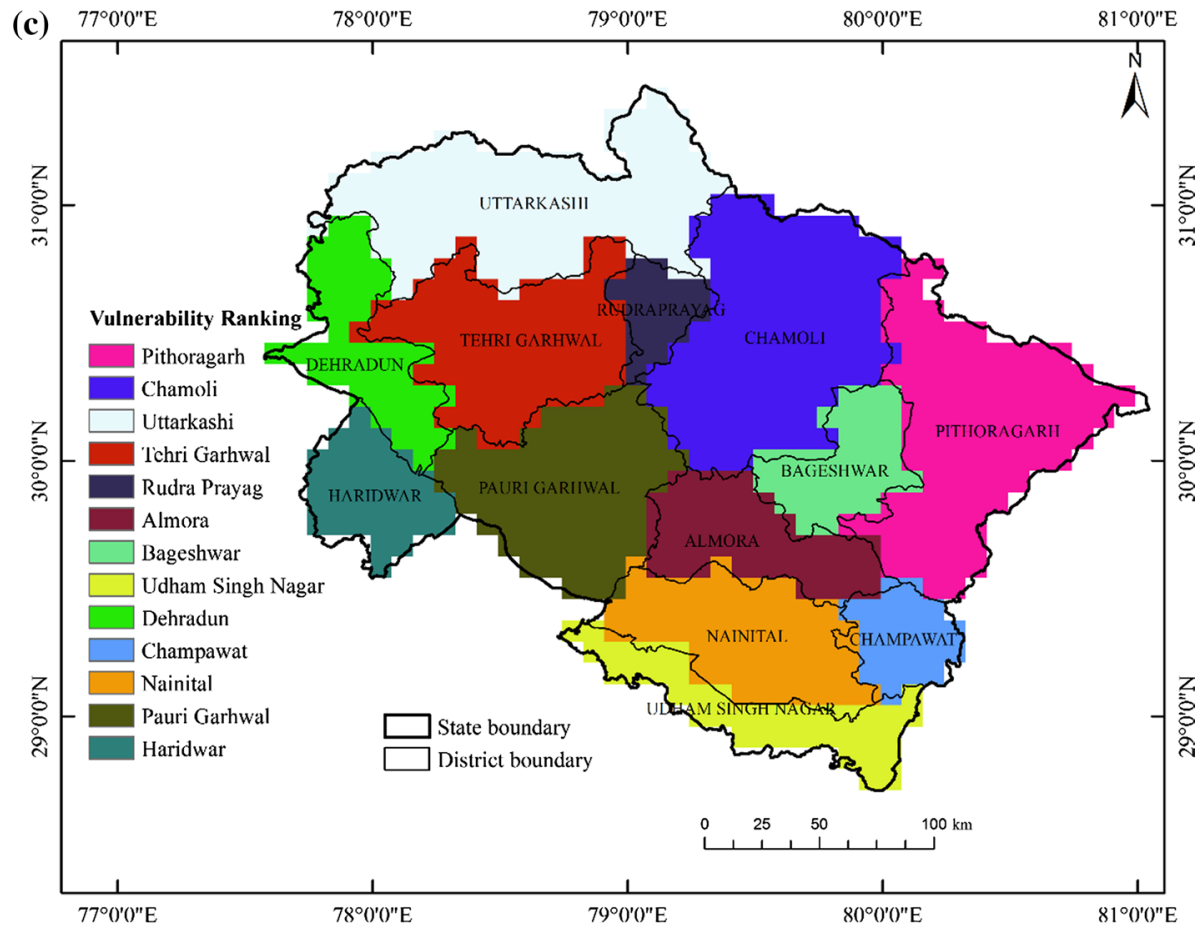

Fig. 12 (continued)

Table 2 Ranking of districts for the sensitivity, adaptability and vulnerability (in decreasing order) based on the analysis of productivity (NPP) for the period 2004-2014

\begin{tabular}{|c|c|c|}
\hline Sensitivity ranking & Adaptability ranking & $\begin{array}{l}\text { Vulnerability ranking (forest } \\
\text { cover \% of geographical } \\
\text { area) }\end{array}$ \\
\hline Pithoragarh & Nainital & Pithoragarh (29.31) \\
\hline Chamoli & Udham Singh Nagar & Chamoli (33.74) \\
\hline Uttarkashi & Dehradun & Uttarkashi (37.77) \\
\hline Tehri Garhwal & Champawat & Tehri Garhwal (56.70) \\
\hline Rudraprayag & Pauri Garhwal & Rudraprayag (57.51) \\
\hline Almora & Haridwar & Almora (54.64) \\
\hline Bageshwar & Almora & Bageshwar (56.27) \\
\hline Udham Singh Nagar & Tehri Garhwal & Udham Singh Nagar (17.15) \\
\hline Dehradun & Uttarkashi & Dehradun (51.98) \\
\hline Champawat & Chamoli & Champawat (69.31) \\
\hline Nainital & Rudraprayag & Nainital (71.70) \\
\hline Pauri Garhwal & Pithoragarh & Pauri Garhwal (56.70) \\
\hline Haridwar & Bageshwar & Haridwar (24.92) \\
\hline
\end{tabular}

${ }^{\mathrm{a}}$ FSI (2017) 
Acknowledgements Authors acknowledge the support received from Forest Research Institute (FRI), Dehradun to accomplish the study and access to its GIS Centre for processing remotely sensed data and cartographical works.

Open Access This article is distributed under the terms of the Creative Commons Attribution 4.0 International License (http://creativecommons.org/licenses/by/4.0/), which permits unrestricted use, distribution, and reproduction in any medium, provided you give appropriate credit to the original author(s) and the source, provide a link to the Creative Commons license, and indicate if changes were made.

\section{References}

Adger WN (2006) Vulnerability. Glob Environ Chang 16:268-281

Alwang J, Siegel PB, Jorgensen SL (2001) Vulnerability: a view from different disciplines. Social protection discussion paper series, vol 115, p 60

Bala G, Joshi J, Chaturvedi RK et al (2013) Trends and variability of AVHRR-derived NPP in India. Remote Sens 5:810-829

Bertin RI (2008) Plant phenology and distribution in relation to recent climate change. J Torrey Bot Soc 135:126-146

Bhutiyani MR, Kale VS, Pawar NJ (2007) Long-term trends in maximum, minimum and mean annual air temperatures across the Northwestern Himalaya during the twentieth century. Clim Change 85:159-177

Blaikie P, Cannon T, Davis I, Wisner B (2014) At risk: natural hazards, people's vulnerability and disasters. Routledge, New York

Cao M, Prince SD, Small J, Goetz SJ (2004) Remotely sensed interannual variations and trends in terrestrial net primary productivity 1981-2000. Ecosystems 7:233-242

Champion HG, Seth SK (1968) A revised survey of the forest types of India. Government of India Publication, New Delhi

Chaturvedi RK, Gopalakrishnan R, Jayaraman M et al (2011) Impact of climate change on Indian forests: a dynamic vegetation modeling approach. Mitig Adapt Strateg Glob Chang 16:119-142. https://doi. org/10.1007/s11027-010-9257-7

Chhabra A, Dadhwal VK (2004) Estimating terrestrial net primary productivity over India using satellite data. Curr Sci 86:269-271

Costanza R, d'Arge R, De Groot R et al (1998) The value of ecosystem services: putting the issues in perspective. Ecol Econ 25:67-72

Costanza R, Fisher B, Mulder K et al (2007) Biodiversity and ecosystem services: a multi-scale empirical study of the relationship between species richness and net primary production. Ecol Econ 61:478-491

Coulson D, Joyce L (2006) Indexing variability: a case study with climate change impacts on ecosystems. Ecol Indic 6:749-769

Cramer W, Kicklighter DW, Bondeau A et al (1999) Comparing global models of terrestrial net primary productivity (NPP): overview and key results. Glob Chang Biol 5:1-15

Daac O (2008) MODIS collection 5 land products global subsetting and visualization tool. ORNL DAAC, Oak Ridge

Devi RM, Patasaraiya MK, Sinha B et al (2018) Understanding the linkages between climate change and forest. Curr Sci 114:987-996

FSI (2015) Forest and Tree Resources in States and Union Territories. Forest Survey of India, Ministry of Environment, Forest and Climate Change, Government of India, Dehradun. In: Indian State of Forest Report, 2015, p 181

FSI (2017) India state of forest report 2017. Forest Survey of India, Ministry of Environment, Forest and Climate Change. Government of India, Dehradun

FSI (2011) Forest Types of India. Forest Survey of India, Ministry of Environment, Forest and Climate Change. Government of India, Dehradun

Füssel H-M (2007) Vulnerability: a generally applicable conceptual framework for climate change research. Glob Environ Chang 17:155-167

Gallopín GC (2006) Linkages between vulnerability, resilience, and adaptive capacity. Glob Environ Chang 16:293-303 
Gerlitz J-Y, Macchi M, Brooks N et al (2017) The Multidimensional Livelihood Vulnerability Index-an instrument to measure livelihood vulnerability to change in the Hindu Kush Himalayas. Clim Dev 9:124-140

Gopalakrishnan R, Jayaraman M, Bala G, Ravindranath NH (2011) Climate change and Indian forests. Curr Sci 101:348-355

Harris I, Jones PD, Osborn TJ, Lister DH (2014) Updated high-resolution grids of monthly climatic observations-the CRU TS3. 10 Dataset. Int J Climatol 34:623-642

IPCC (2014) Climate change 2014: Mitigation of Climate Change. Working Group III Contribution to the Fifth Assessment Report of the Intergovernmental Panel on Climate Change

Jha S, Srivastava R (2018) Impact of drought on vegetation carbon storage in arid and semi-arid regions. Remote Sens Appl: Soc Environ 11:22-29

Kumar M, Rawat S, Singh H et al (2018) Dynamic forest vegetation models for predicting impacts of climate change on forests: an Indian perspective. Indian J For 41:1-12

Kurosaki T (2010) Targeting the vulnerable and the choice of vulnerability measures: review and application to Pakistan. Pak Dev Rev 49:87-103

Li S, Lü S, Liu Y et al (2015) Variations and trends of terrestrial NPP and its relation to climate change in the 10 CMIP5 models. J Earth Syst Sci 124:395-403

Malik ZA, Pandey R, Bhatt AB (2016) Anthropogenic disturbances and their impact on vegetation in Western Himalaya, India. J Mt Sci 13:69-82

McCarthy JJ (2001) Climate change 2001: impacts, adaptation, and vulnerability: contribution of Working Group II to the third assessment report of the Intergovernmental Panel on Climate Change. Cambridge University Press, Cambridge

Ministry of Environment \& Forests G of I (2010) INCCA: Indian network for climate change assessment. Climate change and India: a $4 \times 4$ assessment

Myneni RB, Keeling CD, Tucker CJ et al (1997) Increased plant growth in the northern high latitudes from 1981 to 1991 . Nature $386: 698$

Nayak RK, Patel NR, Dadhwal VK (2010) Estimation and analysis of terrestrial net primary productivity over India by remote-sensing-driven terrestrial biosphere model. Environ Monit Assess 170:195-213

Pan S, Tian H, Dangal SRS et al (2015) Impacts of climate variability and extremes on global net primary production in the first decade of the 21st century. J Geogr Sci 25:1027-1044

Pandey R (2013) Indices for measuring forest ecosystem goods and services contribution to the rural community: a tool for informed decisions. J Environ Prof Sri Lanka 1(2):58-75

Pandey R, Bardsley DK (2015) Social-ecological vulnerability to climate change in the Nepali Himalaya. Appl Geogr 64:74-86

Pandey R, Harrison S, Gupta AK (2014) Resource availability versus resource extraction in forests: analysis of forest fodder system in forest density classes in lower Himalayas, India. Small-Scale For 13:267-279

Pandey R, Jha S (2012) Climate vulnerability index - measure of climate change vulnerability to communities: a case of rural Lower Himalaya, India. Mitig Adapt Strateg Glob Chang 17:487-506. https://doi. org/10.1007/s11027-011-9338-2

Parry M, Canziani O, Palutikof J et al (2007) Climate change 2007: impacts, adaptation and vulnerability. Cambridge University Press, Cambridge

Pau S, Wolkovich EM, Cook BI et al (2011) Predicting phenology by integrating ecology, evolution and climate science. Glob Chang Biol 17:3633-3643

Quillet A, Peng C, Garneau M (2010) Toward dynamic global vegetation models for simulating vegetationclimate interactions and feedbacks: recent developments, limitations, and future challenges. Environ Rev 18:333-353. https://doi.org/10.1139/A10-016

Ravindranath NH, Sukumar R (1996) Impacts of climate change on forest cover in India. Commonw For Rev 75:76-79

Rew R, Davis G (1990) NetCDF: an interface for scientific data access. IEEE Comput Graph Appl 10:76-82

Running SW, Mu Q, Zhao M (2015) MOD17A3H MODIS/Terra Net Primary Production Yearly L4 Global $500 \mathrm{~m}$ SIN Grid V006. NASA EOSDIS Land Processes DAAC

Schulzweida U, Kornblueh L, Quast R (2006) CDO user's guide

Sharma J, Chaturvedi RK, Bala G, Ravindranath NH (2013) Challenges in vulnerability assessment of forests under climate change. Carbon Manag 4:403-411

Sharma J, Chaturvedi RK, Bala G, Ravindranath NH (2015) Assessing “inherent vulnerability" of forests: a methodological approach and a case study from Western Ghats, India. Mitig Adapt Strateg Glob Chang 20:573-590. https://doi.org/10.1007/s11027-013-9508-5

Sharma J, Upgupta S, Jayaraman M et al (2017) Vulnerability of forests in India: a national scale assessment. Environ Manag 60:544-553

UAPCC (2014) Uttarakhand Action Plan on Climate Change 'Transforming Crisis into Opportunity.' 
Upgupta S, Sharma J, Jayaraman M et al (2015) Climate change impact and vulnerability assessment of forests in the Indian Western Himalayan region: a case study of Himachal Pradesh, India. Clim Risk Manag 10:63-76. https://doi.org/10.1016/j.crm.2015.08.002

Yongxiang Z, Bo T, Li Y (2015) Assessment on the vulnerability of different ecosystems to extreme rainfalls in the middle and lower reaches of Yangtze River. Theor Appl Climatol 121:157-166

Zhang J, Sun J, Ma B, Du W (2017) Assessing the ecological vulnerability of the upper reaches of the Minjiang River. PLoS ONE 12:e0181825

Zhang Y, Qi W, Zhou C et al (2014) Spatial and temporal variability in the net primary production of alpine grassland on the Tibetan Plateau since 1982. J Geogr Sci 24:269-287

\section{Affiliations}

\section{Manoj Kumar ${ }^{1}$ (D) Savita $^{2} \cdot$ Hukum Singh $^{3} \cdot$ Rajiv Pandey $^{4} \cdot$ M. P. Singh ${ }^{5}$. N. H. Ravindranath ${ }^{6} \cdot$ Naveen Kalra $^{7}$}

1 Forest Informatics Division, Geomatics Centre, Forest Research Institute (FRI), PO: New Forest, Dehradun 248006, India

2 Ecology, Climate Change and Forest Influence Division, Forest Research Institute, PO: New Forest, Dehradun 248006, India

3 Ecology, Climate Change and Forest Influence Division, Forest Research Institute, PO: New Forest, Dehradun 248006, India

4 Forest Informatics Division, Forest Research Institute, PO: New Forest, Dehradun 248006, India

5 Climate Change and Forest Influence Division, Forest Research Institute, PO: New Forest, Dehradun 248006, India

6 Centre for Sustainable Technology, Indian Institute of Science (IISc), Bangalore, India

7 Agriculture Physics Division, Indian Agricultural Research Institute, Pusa, New Delhi, India 